\title{
Empirical estimation of the molecular weight of gold
}

\section{complexes in solution by pulsed-field gradient NMR}

\author{
Ghanem Hamdoun, ${ }^{a}$ Christophe Bour, ${ }^{b}$ Vincent Gandon, ${ }^{b, c}$ Jean-Nicolas Dumez ${ }^{a *}$
}

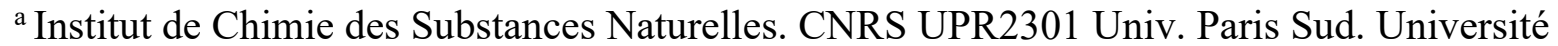
Paris-Saclay. 91190 Gif-Sur-Yvette France.

b Institut de Chimie Moléculaire et des Matériaux d'Orsay. CNRS UMR 8182. Univ. Paris Sud. Université Paris-Saclay. 91405 Orsay France.

${ }^{c}$ Laboratoire de Chimie Moléculaire, CNRS UMR 9168, Ecole Polytechnique, Université ParisSaclay, route de Saclay, 91128 Palaiseau cedex, France.

KEYWORDS: Gold catalysis, NMR spectroscopy, DOSY, ion pairing, PFG NMR

ABSTRACT. Homogenous gold catalysis has emerged as a powerful tool in organic synthesis, but many mechanistic questions in that area remain unanswered. The ability of diffusion-ordered NMR spectroscopy (DOSY) to investigate interactions between substrates, to study molecular assemblies, as well as to characterize reactive intermediates, makes it a powerful technique to get a better understanding of gold-catalyzed processes. In this article, we show that a simple empirical approach makes it possible to derive estimates of the molecular weight of gold complexes from their translational diffusion coefficients measured with DOSY. This approach is 
based on external calibration curves (ECC), modified to take into account the molecular density of gold complexes. The estimated molecular weights in turn provide information on interactions, as illustrated here notably with ion pairing, and have the potential to provide key information to rationalize the reactivity of reagents in gold-catalysed reactions.

\section{INTRODUCTION}

Over the past 18 years, gold catalysis has opened new perspectives in organic chemistry and has played a key role in the synthesis of complex molecules from simple precursors. ${ }^{1-17}$ While gold(I) and gold(III) complexes have been considered as inert for a long time, a tremendous number of studies now clearly demonstrates the great interest of gold derivatives in homogeneous catalysis. This synthetic work has been supported by coordination chemistry efforts, which have identified various families of neutral or cationic mono- or digold complexes that are now broadly applied and easily available from commercial sources. One of the most salient features of gold complexes is their ability to activate $\mathrm{CC} \pi$ bonds (alkynes, alkenes or allenes) towards nucleophilic attack. This means that the coordination of a soft $\mathrm{CC} \pi$ bond to a soft gold-based Lewis acid renders the LUMO of the substrate, such as an alkyne, more accessible to the HOMO of a variety of nucleophiles. However, the choice of ligands, counterions, solvent and other experimental parameters is still a tedious task. Although high levels of selectivity are usually observed, anticipation and rationalization of the outcome of goldcatalyzed reactions also remain a challenge. To gain a deeper insight into gold-catalyzed transformations, intensive mechanistic work has been provided. On several occasions, it has been shown that the mechanisms are more complex than originally thought. For instance, it is now clearly established that the counterions of cationic gold catalysts can play a dramatic influence on the selectivity, ${ }^{13}$ or that some reactions actually require several catalyst molecules to activate 
the substrates. In this context, the arsenal of spectroscopy and spectrometry techniques at the chemists' disposal to analyse the mechanisms of gold-catalyzed transformations without affecting the catalytic process is still incomplete.

Nuclear magnetic resonance (NMR) spectroscopy is a powerful method for the noninvasive analysis of molecules in solution. Pulsed-field gradient (PFG) NMR and its implementation DOSY (for diffusion-ordered NMR spectroscopy) ${ }^{18}$ are a particularly relevant approach for the analysis of organometallic compounds in solution. DOSY provides, for each peak of an NMR spectrum, an estimate of the translational diffusion coefficients of the corresponding molecules. For the interpretation of these coefficients, several techniques are available that provide information on molecular sizes and shapes. ${ }^{19-21}$ Typically, the StokesEinstein equation $^{22}$, or a derivative thereof, is used to estimate hydrodynamic radii, and this approach has proven very successful for the analysis of organometallic compounds with, for example, the characterisation of ion pairs. ${ }^{23-25}$ For gold complexes, recent examples include the analysis of the bonding mode of cationic gold(I) species in solution, ${ }^{26}$ and the study of counterion effects. ${ }^{27}$ Alternatively, empirical relationships can be established to obtain estimates of molecular weights from measured diffusion coefficients. Such relationships may also be derived from the Stokes-Einstein equation. ${ }^{28,} 29$ More accurate results are usually obtained with power laws of the form $D=K . \mathrm{MW}^{\alpha},{ }^{30}$ where $K$ and $\alpha$ are coefficients which are, however, specific of a given class of compounds and require a calibration. ${ }^{31-33} \mathrm{~A}$ first option is to derive an internal calibration curves (ICC) by including multiple reference molecules in the sample. ${ }^{31,33}$ Applications of this approach have given information on, e.g., the aggregation state of organolithium complexes in solution, ${ }^{31,34}$ and its solvation degree. ${ }^{35}$ Recently, Stalke and coworkers have proposed to replace the use of multiple internal references by a single internal 
reference, which may be the solvent, used together with external calibration curves. ${ }^{36-39}$ The use of a reference and a normalisation step makes it possible to derive calibration curves that are largely independent of the reference, temperature and other experimental parameters. Application of the ECC approach have been reported in organolithium chemistry to provide a reliable and straightforward indication of aggregation state of lithium diisopropylamide in hydrocarbon solvents. ${ }^{40}$ The validity of a given calibration curve, however, is still restricted to specific classes of compounds.

In this article, we show that important pieces of information on the interaction between cationic gold(I) complexes and their counterion or the substrate can be obtained using pulsedfield gradient NMR, together with external calibration curves (ECC). The accuracy of the ECC approach is highly dependent on the choice of model parameters, and new ECCs are derived here using a set of gold-containing compounds. These relationships are then used to estimate the molecular weights of gold complexes in solution from their diffusion coefficients. With the example of several cationic gold catalysts, we show that PFG NMR with ECC gives information on the type of ion pairing in solution with no need to observe the counterion by NMR. The interactions of gold complexes with several alkynes are also analysed.

\section{RESULTS AND DISCUSSION}

As mentioned above, external calibration curves have been shown to be applicable for a specific range of "molecular density", where the molecular density can be defined as the ratio of the molecular weight over the sum of the van der Waals volume of the atoms in the molecule. ${ }^{36}$ Existing calibration curves were derived from molecules composed of carbon, hydrogen and heteroatoms of the third period, with molecular densities in the $4-6 \times 10^{29} \mathrm{~g} /\left(\mathrm{mol} . \mathrm{m}^{3}\right)$ range. Unsurprisingly, when these calibration curves were applied to gold complexes, large systematic 
errors were obtained. For example, for the complex (JohnPhos)AuCl, which is widely used in gold catalysis, using the existing ECC for dichloromethane solutions, the estimated molecular weight was $442 \mathrm{~g} / \mathrm{mol}$, while the correct value is $531 \mathrm{~g} / \mathrm{mol}$, corresponding to a relative error of $20.1 \%$. With a van der Waals radius of $166 \mathrm{pm}$ and an atomic weight of $196 \mathrm{~g} / \mathrm{mol}$, the gold atom has a molecular density of $1.03 \times 10^{31} \mathrm{~g} /\left(\mathrm{mol} . \mathrm{m}^{3}\right)$, far outside the range covered by existing calibration curves.

Table 1. Gold complexes used to derive external calibration curves. For each compound, the molecular density (MD) and the molecular weight (MW) is given.

\begin{tabular}{llll} 
& $\mathrm{Complex}^{[\mathrm{a}]}$ & $\mathrm{MD} \mathrm{g} /\left(\mathrm{mol} . \mathrm{m}^{3}\right)$ & $\mathrm{MW}(\mathrm{g} / \mathrm{mol})$ \\
\hline $\mathbf{a}$ & $\left(\mathrm{Et}_{3} \mathrm{P}\right) \mathrm{AuCl}$ & $1.28 \times 10^{30}$ & 350 \\
$\mathbf{b}$ & $\left(t \mathrm{Bu}_{3} \mathrm{P}\right) \mathrm{AuCl}$ & $9.38 \times 10^{29}$ & 434 \\
$\mathbf{c}$ & $\left(\mathrm{Ph}_{3} \mathrm{P}\right) \mathrm{AuCl}$ & $9.51 \times 10^{29}$ & 494 \\
$\mathbf{d}$ & $(\mathrm{IPr}) \mathrm{AuCl}$ & $7.49 \times 10^{29}$ & 621 \\
$\mathbf{e}$ & $(\mathrm{Phosphite}) \mathrm{AuCl}$ & $6.63 \times 10^{29}$ & 879 \\
$\mathbf{f}$ & $(\mathrm{CDP}) \mathrm{AuCl}$ & $7.51 \times 10^{29}$ & 769 \\
$\mathbf{g}$ & $(\mathrm{IPr}) \mathrm{AuOH}$ & $7.29 \times 10^{29}$ & 602 \\
$\mathbf{h}$ & $(R, R)-(\mathrm{DIOP})-(\mathrm{AuCl})_{2}$ & $9.85 \times 10^{29}$ & 963 \\
$\mathbf{i}$ & $(\mathrm{CDP})-(\mathrm{AuCl})_{2}$ & $9.44 \times 10^{29}$ & 1001 \\
$\mathbf{j}$ & $(R)-(\mathrm{DM}-\mathrm{SEGPHOS})-(\mathrm{AuCl})_{2}$ & $8.59 \times 10^{29}$ & 1188 \\
$\mathbf{k}$ & $(R)-(\mathrm{DTBM}-\mathrm{SEGPHOS})-(\mathrm{AuBr})_{2}$ & $7.41 \times 10^{29}$ & 1733 \\
$\mathbf{l}$ & $(R)-(\mathrm{TolBINAP})-(\mathrm{AuCl})_{2}$ & $8.52 \times 10^{29}$ & 1145 \\
$\mathbf{m}$ & $(R)-(\mathrm{DTBM}-\mathrm{SEGPHOS})-(\mathrm{AuCl})_{2}$ & $7.06 \times 10^{29}$ & 1644
\end{tabular}

[a] See ESI for the structure of the complexes

In order to assess the possibility to establish an empirical relation between molecular weight and normalized diffusion coefficient that would be applicable to gold catalysts, a series of DOSY experiments was carried out on a selection of 13 di- and monogold complexes, listed in Table 1. For this study, the experiments were performed in deuterated dichloromethane, which is a very common solvent in gold catalysis. The use of external calibration curves requires a single internal standard. Common choices for the internal standard include the residual, partially 
undeuterated solvent, as well as relatively inert molecules, such as adamantane, cyclopentane, tetramethylsilane or naphthalene. Here, in order to establish the external calibration curves, the measured diffusion coefficients were normalised against adamantane. The "fixed" value for the diffusion coefficient of the reference $\left(\mathrm{D}_{\text {ref,fix }}\right)$ were estimated by using the average $\log \mathrm{D}$ value of 13 DOSY measurements of $33 \mathrm{mM}$ solution at $25^{\circ} \mathrm{C}$ (Table 2 ).

Table 2. Values of the "fixed" diffusion coefficients for the two compounds used as internal references

\begin{tabular}{ll} 
Internal reference & $\log D_{\text {ref,fix }}$ \\
\hline adamantane in $\mathrm{CD}_{2} \mathrm{Cl}_{2}$ & -8.82 \\
$\mathrm{CH}_{2} \mathrm{Cl}_{2}$ in $\mathrm{CD}_{2} \mathrm{Cl}_{2}$ & -8.63
\end{tabular}

Figure 1 shows the normalised diffusion coefficients for a set of 13 gold complexes, plotted against the known molecular weight of each compound. Molecular weights actually range from 350 to $1733 \mathrm{~g} / \mathrm{mol}$, and molecular densities from $6.63 \times 10^{29}$ to $12.8 \times 10^{29} \mathrm{~g} /\left(\mathrm{mol} . \mathrm{m}^{3}\right)$.

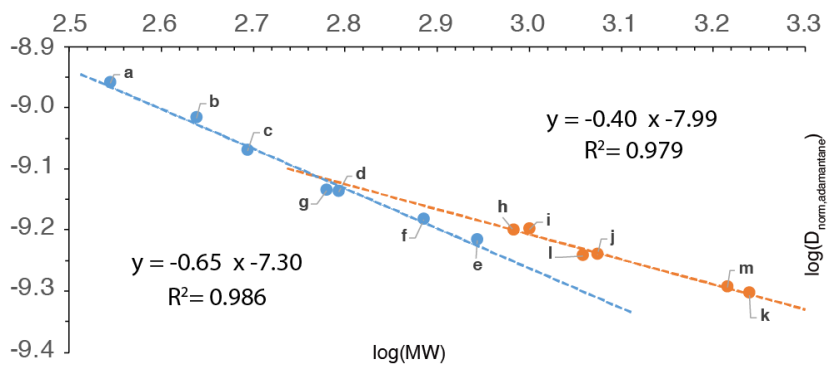

Figure 1. $\log D$ versus $\log \mathrm{MW}$ in $\mathrm{CD}_{2} \mathrm{Cl}_{2}$. All compounds were normalized to $\log D_{\text {ref,fix }}$ (adamantane)

A qualitative analysis revealed that the data in Figure 1 may not be described accurately with a single linear relationship. However, when a separation was made between mono- and digold complexes, a linear relationship was obtained within each group. The parameters for these relationships are summarised in Table 3. Importantly, they may be used to obtain estimates of 
molecular weights from measured diffusion coefficients, with no need for an additional samplespecific calibration procedure.

Table 3. Parameters for the external calibration curves derived from diffusion coefficients of gold complexes in $\mathrm{CD}_{2} \mathrm{Cl}_{2}$.

\begin{tabular}{llll} 
& $-\log K$ & $-a$ & $R^{2}$ \\
\hline Mono-metallic gold complexes & 7.30 & 0.65 & 0.986 \\
Bi-metallic gold complexes & 7.99 & 0.40 & 0.979
\end{tabular}

The difference in parameters for the calibration curves of mono- and digold complexes may have two different origins. A comparison of the molecular densities of the mono- and digold species shows that the difference in calibration does not arise from it; the average molecular densities for the two groups of complexes differ by less than $3 \%$. On the other hand, the monoand digold complexes have a different overall shape. Qualitatively, mono-metallic complexes are mostly spherical-like molecules, while digold complexes have a more elongated shape. This can be appreciated in the three-dimensional structure of the compound, shown in the SI. 

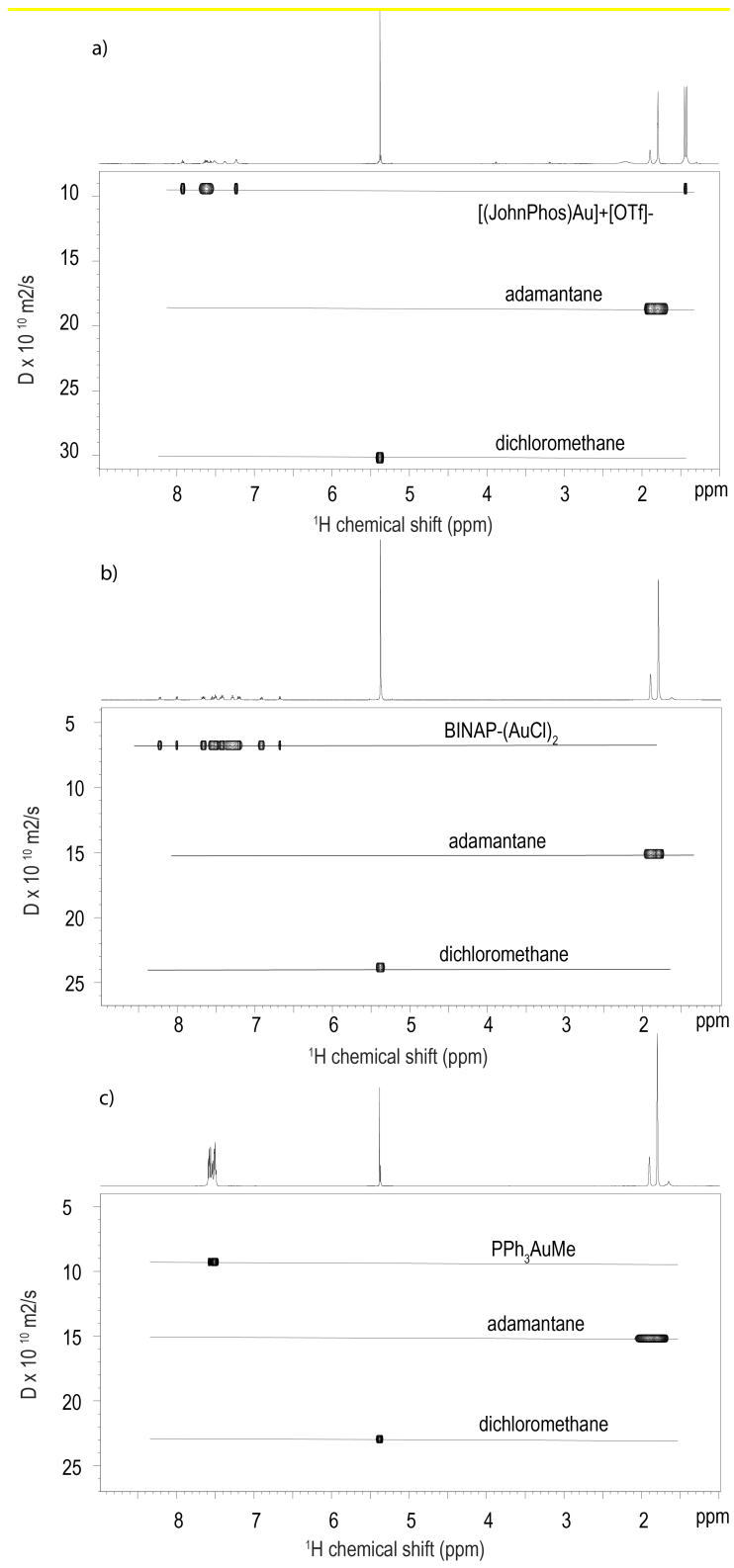

Figure 2. ${ }^{1} \mathrm{H}$ DOSY NMR of (a) $[(\mathrm{JohnPhos}) \mathrm{Au}]+[\mathrm{OTf}]-$, (b) (BINAP)-(AuCl) 2 and (c) $\left(\mathrm{Ph}_{3} \mathrm{P}\right) \mathrm{AuMe}$ complexes in $\mathrm{CD}_{2} \mathrm{Cl}_{2}$ with internal references (adamantane).

The validity of the proposed external calibration curves has then been checked using the estimate of the molecular weights of compounds that were left out of the data set for the linear regressions shown in Figure 1. Table 4 shows the estimated molecular weights for $\left(\mathrm{Ph}_{3} \mathrm{P}\right) \mathrm{AuMe}$ as mono-metallic complex and $\mathrm{R}-(\mathrm{BINAP})-(\mathrm{AuCl})_{2}$ as bimetallic complex, obtained from the diffusion measurements shown in Figure 2, with adamantane as internal reference. For both 
compounds, the estimated molecular weight differs from the known value by $3.7 \%$ and $0.4 \%$ when using the calibration curve derived from the corresponding number of gold atoms. In contrast, using the calibration curve derived for low-density compounds ("classical ECC"), errors of 25 to $45 \%$ were observed, depending on the predicted shape (Table 4). Conversely, large errors were also observed when the ECC derived for mono-gold species was used for the di-gold species.

Table 4. Comparison between the calculated and the estimated molecular weights for two gold complexes using adamantane as a reference and the ECCs of ref. 12d ("classic"-ECC) or the ECCs introduced here for mono- (G1) or digold (G2) complexes.

\begin{tabular}{lllllll} 
& \multirow{2}{*}{$\begin{array}{l}\text { MW } \\
(\mathrm{g} / \mathrm{mol})\end{array}$} & \multicolumn{2}{l}{$\begin{array}{l}\text { MWest }(\mathrm{g} / \mathrm{mol}) \\
\text { "classic"-ECC }\end{array}$} & \multicolumn{2}{c}{ "gold"-ECC } \\
\cline { 3 - 7 } & & Merge & DSE & ED & G1 & G2 \\
\hline (BINAP)-(AuCl) $)_{2}$ & 1087 & 751 & 664 & 561 & 864 & 1083 \\
$\left(\mathrm{Ph}_{3} \mathrm{P}\right)$ AuMe & 474 & 377 & 351 & 347 & 492 & 437
\end{tabular}

* Merge (Merged calibration curves can be used if molecular shape is unknown), DSE (dissipated spheres and ellipsoids), ED (expanded discs)

One of the proposed advantages of the ECC approach is the possibility to use a variety of internal references, with no need to recalculate the calibration curve. Table 5 shows the estimated molecular weights for the compounds analysed above, using now the measured diffusion coefficient of the solvent as a reference. Strikingly, the results are comparable to those obtained using adamantane, with errors of $0.6 \%$ and $4.8 \%$ for the estimated molecular weights.

Table 5. Comparison between the calculated and the estimated molecular weights for two gold complexes using $\mathrm{CD}_{2} \mathrm{Cl}_{2} / \mathrm{CH}_{2} \mathrm{Cl}_{2}$ as a reference and the ECCs of ref. ${ }^{39}$ ("classic"-ECC) or the ECCs introduced here for mono (G1)- or digold (G2) complexes. 


\begin{tabular}{lllllll} 
& \multirow{2}{*}{$\begin{array}{l}\text { MW } \\
(\mathrm{g} / \mathrm{mol})\end{array}$} & \multicolumn{2}{l}{$\begin{array}{l}\text { MW } \\
\text { "ccst }(\mathrm{g} / \mathrm{mol})\end{array}$} & \multicolumn{2}{c}{ “gold"-ECC } \\
\cline { 3 - 7 } & & Merge & DSE & ED & G1 & G2 \\
\hline (BINAP)-(AuCl $)_{2}$ & 1087 & 760 & 672 & 566 & 858 & 1037 \\
$\left(\mathrm{Ph}_{3} \mathrm{P}\right) \mathrm{AuMe}$ & 474 & 359 & 335 & 335 & 477 & 430
\end{tabular}

One of the main potential applications of our ECCs is in the analysis of molecular interactions in gold-catalysed reactions. The estimated molecular weight of a chemical species gives information on its association with other compounds. This is illustrated here with a cationic gold complex, obtained in situ by reacting (JohnPhos) $\mathrm{AuCl}$ with $\mathrm{AgOTf}$ in $\mathrm{CD}_{2} \mathrm{Cl}_{2}$ and filtering the $\mathrm{AgCl}$ precipitate. Using the ECC derived with mono-gold species and adamantane as an internal reference, the estimated molecular weight is $611 \mathrm{~g} / \mathrm{mol}$, as shown in Table 6 . Compared with the actual molecular weight of $[(\mathrm{JohnPhos}) \mathrm{Au}]^{+}, 495 \mathrm{~g} / \mathrm{mol}$, and that of the ion pair formed with the counterion $[(\mathrm{JohnPhosAu})]^{+}[\mathrm{OTf}]^{-}, 644 \mathrm{~g} / \mathrm{mol}$, the best agreement clearly is with the ion pair. This is a firm indication of a strong association in solution. This observation can be validated by performing a ${ }^{19} \mathrm{~F}$ PFG NMR experiment. Figure 3 shows that the measured diffusion coefficient obtained from the [OTf] ${ }^{-}$ion ${ }^{19} \mathrm{~F}$ nuclei is close to that obtained for the JohnPhos ${ }^{1} \mathrm{H}$ signals. This example illustrates the usefulness of external calibration curves, with which the type of pairing can be characterised by observing just one of the partners. Similar results and information were obtained with two other examples, with a phosphine and a NHC (N-Heterocyclic Carbene) ligand, shown in Table 6 (mixtures on row 5 and 9).

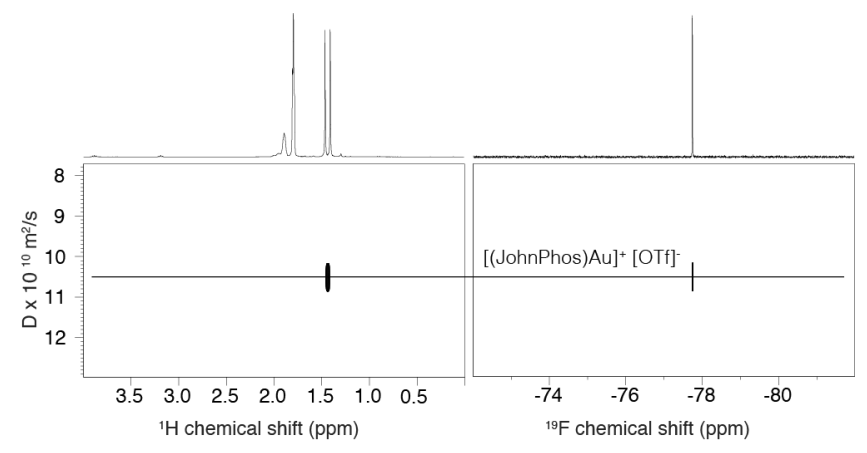


Figure 3. ${ }^{19} \mathrm{~F}$ and ${ }^{1} \mathrm{H}$ DOSY for $[(\text { JohnPhos }) \mathrm{Au}]^{+}[\mathrm{OTf}]^{-}$catalyst in $\mathrm{CD}_{2} \mathrm{Cl}_{2}$.

A further step can be taken with the analysis of mixtures containing a cationic gold complex and an excess of alkyne, which would be representative of the numerous gold-catalysed alkyne transformations reported in the literature. ${ }^{41-43}$ Table 6 also shows the diffusion coefficients measured from a ligand ${ }^{1} \mathrm{H}$ signals of gold complexes after addition of an alkyne, for three complexes and two alkynes. In five cases, the estimated molecular weights obtained with the G1ECC curve reveal that the cationic gold complex strongly associates with the alkyne, with a deviation of less than $6 \%$ between the estimated and the calculated molecular weight of the adducts. This corresponds to the expected formation of gold $\pi$-alkyne complexes, ${ }^{44-46}$ which is central to a number of important gold-catalysed reactions. This process, however, also depends on alkyne substitution, on the nature, and on the structure of the ligand.

Table 6. Comparison between the calculated and the estimated molecular weights for three gold complexes. The estimated molecular weights were obtained from a normalised diffusion coefficient measured in $\mathrm{CD}_{2} \mathrm{Cl}_{2}$, using adamantane as an internal reference, and the "gold"-ECCs for mono- or digold complexes

\begin{tabular}{|c|c|c|c|c|c|}
\hline \multirow{3}{*}{ Mixture } & \multirow{3}{*}{ Expected compound } & \multirow{3}{*}{$\begin{array}{l}\text { calculated } \\
\text { MW } \\
(\mathrm{g} / \mathrm{mol})\end{array}$} & \multicolumn{2}{|c|}{$\begin{array}{c}\text { estimated } \\
\mathrm{MW}(\mathrm{g} / \mathrm{mol})\end{array}$} & \multirow[t]{3}{*}{$\Delta \%$} \\
\hline & & & \multicolumn{2}{|c|}{ "gold"-ECC } & \\
\hline & & & G1 & $\mathrm{G} 2$ & \\
\hline (JohnPhos)AuCl & - & 531 & 561 & - & 5.3 \\
\hline $\begin{array}{l}\text { (JohnPhos)AuCl }+ \\
\text { AgOTf }\end{array}$ & {$[(\mathrm{JohnPhos}) \mathrm{Au}]^{+}[\mathrm{OTf}]^{-}$} & 644 & 611 & - & 5.4 \\
\hline $\begin{array}{l}(\mathrm{JohnPhos}) \mathrm{AuCl}+ \\
\text { AgOTf }+1 \text {-pentyn-1- } \\
\text { ylbenzene }\end{array}$ & $\begin{array}{l}{\left[(\mathrm{JohnPhos}) \mathrm{Au}\left(\mathrm{H}_{7} \mathrm{C}_{3} \mathrm{C} \equiv \mathrm{C}-\right.\right.} \\
\left.\left.\mathrm{C}_{6} \mathrm{H}_{5}\right)\right]^{+}[\mathrm{OTf}]^{-}\end{array}$ & 788 & 770 & - & 2.3 \\
\hline (JohnPhos)AuCl + & {$[(\mathrm{JohnPhos}) \mathrm{Au}(\mathrm{HC} \equiv \mathrm{C}-$} & 746 & 786 & - & 5.1 \\
\hline
\end{tabular}




\begin{tabular}{|c|c|c|c|c|c|}
\hline AgOTf + & $\left.\left.\mathrm{C}_{6} \mathrm{H}_{5}\right)\right]^{+}[\mathrm{OTf}]^{-}$ & & & & \\
\hline (IPr) $\mathrm{AuCl}$ & - & 622 & 638 & - & 2.5 \\
\hline (IPr)AuCl $+\mathrm{AgOTf}$ & {$[(\mathrm{IPr}) \mathrm{Au}]^{+}[\mathrm{OTf}]^{-}$} & 736 & 699 & - & 5 \\
\hline $\begin{array}{l}\text { (IPr)AuCl }+\mathrm{AgOTf}+ \\
\text { 1-pentyn-1-ylbenzene }\end{array}$ & $\begin{array}{l}{\left[(\mathrm{IPr}) \mathrm{Au}\left(\mathrm{H}_{7} \mathrm{C}_{3} \mathrm{C} \equiv \mathrm{C}-\right.\right.} \\
\left.\left.\mathrm{C}_{6} \mathrm{H}_{5}\right)\right]^{+}[\mathrm{OTf}]^{-}\end{array}$ & 880 & 833 & - & 5.3 \\
\hline $\begin{array}{l}\text { (IPr)AuCl + AgOTf }+ \\
\text { phenylacetylene }\end{array}$ & {$\left[(\mathrm{IPr}) \mathrm{Au}\left(\mathrm{HC} \equiv \mathrm{C}_{-} \mathrm{C}_{6} \mathrm{H}_{5}\right)\right]^{+}, \mathrm{OTf}^{-}$} & 838 & 1033 & - & 23 \\
\hline & $\begin{array}{l}{\left[\{(\mathrm{IPr}) \mathrm{Au}\}_{2}\left(\eta^{1}, \eta^{2}-\mathrm{C} \equiv \mathrm{C}-\right.\right.} \\
\left.\left.\mathrm{C}_{6} \mathrm{H}_{5}\right)\right]^{+}[\mathrm{OTf}]^{-}\end{array}$ & 1424 & - & 1444 & 1.4 \\
\hline$\left(\mathrm{Ph}_{3} \mathrm{P}\right) \mathrm{AuCl}$ & - & 494 & 501 & - & 1.4 \\
\hline$\left(\mathrm{Ph}_{3} \mathrm{P}\right) \mathrm{AuCl}+\mathrm{AgOTf}$ & {$\left[\left(\mathrm{Ph}_{3} \mathrm{P}\right) \mathrm{Au}\right]^{+}[\mathrm{OTf}]^{-}$} & 610 & 621 & - & 1.8 \\
\hline $\begin{array}{l}\left(\mathrm{Ph}_{3} \mathrm{P}\right) \mathrm{AuCl}+\mathrm{AgOTf}+ \\
\text { 1-pentyn-1-ylbenzene }\end{array}$ & $\begin{array}{l}{\left[\left(\mathrm{Ph}_{3} \mathrm{P}\right) \mathrm{Au}\left(\mathrm{H}_{7} \mathrm{C}_{3} \mathrm{C} \equiv \mathrm{C}-\right.\right.} \\
\left.\left.\mathrm{C}_{6} \mathrm{H}_{5}\right)\right]^{+}[\mathrm{OTf}]^{-}\end{array}$ & 754 & 743 & - & 1.5 \\
\hline $\begin{array}{l}\left(\mathrm{Ph}_{3} \mathrm{P}\right) \mathrm{AuCl}+\mathrm{AgOTf}+ \\
\text { phenylacetylene }\end{array}$ & $\begin{array}{l}{\left[\left(\mathrm{Ph}_{3} \mathrm{P}\right) \mathrm{Au}(\mathrm{HC} \equiv \mathrm{C}-\right.} \\
\left.\left.\mathrm{C}_{6} \mathrm{H}_{5}\right)\right]^{+}[\mathrm{OTf}]^{-}\end{array}$ & 718 & 737 & - & 2.6 \\
\hline
\end{tabular}

Interestingly, the diffusion coefficient and estimated molecular weight obtained for the mixture of complex [(IPr)Au $\left.]^{+}[\mathrm{OTf}]^{-}\right)$and phenylacetylene with the $\mathrm{G} 1-\mathrm{ECC}$ is of $1033 \mathrm{~g} / \mathrm{mol}$, which does not correspond to a simple gold $\pi$-alkyne complex of formula $[(\mathrm{IPr}) \mathrm{Au}(\mathrm{HC} \equiv \mathrm{C}$ $\left.\left.\mathrm{C}_{6} \mathrm{H}_{5}\right)\right]^{+}[\mathrm{OTf}]^{-}$, which has a molecular weight of $796 \mathrm{~g} / \mathrm{mol}$. This is however fully consistent with the observation made by Widenhoeffer et al. Indeed, when [(IPr)Au $]^{+}[\mathrm{OTf}]^{-}$and phenylacetylene were reacted in $\mathrm{CD}_{2} \mathrm{Cl}_{2}$ at $25{ }^{\circ} \mathrm{C}$, the formation of a gold acetylide was observed, in which the alkyne moiety still serves as a $\pi$ ligand for a second gold ion, as in $\left[((\operatorname{IPr}) A u)_{2}-\eta^{1}, \eta^{2}-C \equiv C\right.$ $\left.\mathrm{C}_{6} \mathrm{H}_{5}\right]^{+}[\mathrm{OTf}]^{-}($Scheme 1, 2), evidenced by the disappearance of the acetylenic proton at $\delta=4.56$ ppm in the ${ }^{1} \mathrm{H}$ NMR spectrum as well as by X-ray characterization..$^{44}$ Using the G2-ECC, an estimated molecular weight of $1444 \mathrm{~g} / \mathrm{mol}$ was now obtained, which is consistent with the calculated molecular weight of $1424 \mathrm{~g} / \mathrm{mol}$ for $\mathbf{2}$. This example clearly illustrates the usefulness of the ECC for analysing the structure of gold $\pi$-alkyne complexes.

The use of empirical relations between diffusion coefficients as measured by PFG NMR becomes more complicated when multiple species coexist and interconvert ${ }^{47}$. When chemical 
exchange is fast on the NMR and diffusion-encoding timescales, the apparent diffusion coefficient will be a compromise that depends on the diffusion coefficients and exchange rates of the interconverting species. As a result, an unexpected value of the estimated molecular weight for an organometallic species may also be an indication that chemical exchange is present ${ }^{48}$. The effects of dynamics on apparent diffusion coefficients can be limited by working at low temperature, as was done, for example, in analyses of organolithium compounds ${ }^{49,50}$.

The proposed method can was also assessed for concentrations of the compounds that are closer to those found in catalytic reactions. As shown in the Supporting Information, comparable estimates of molecular weights are obtained, at a concentration ten times smaller, for the cationic gold complexes analysed here and their reaction with an alkyne substrate. Overall, the ECC approach proves very useful from an experimental point of view, as it can provide accurate results without the need to add potentially reactive compounds in the solution.

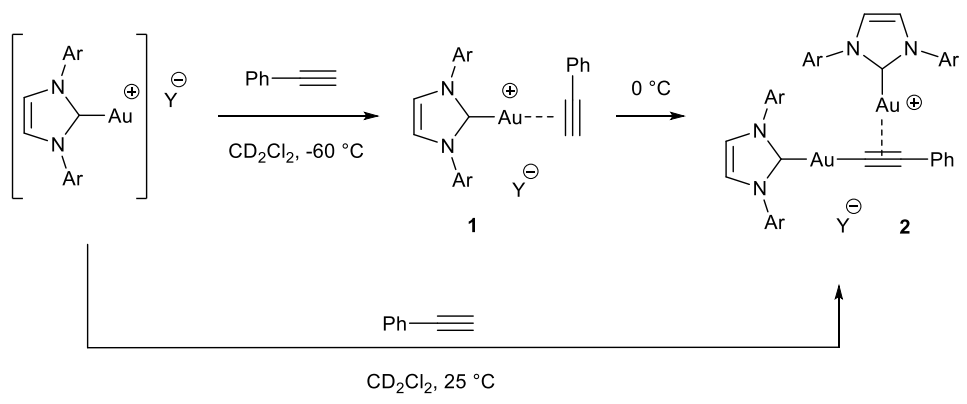

Scheme 1. Ar = 2,6-diisopropylphenyl; $\mathrm{Y}=\mathrm{OTf}$ or $\mathrm{SbF}_{6}$ (see ref.15a)

\section{CONCLUSIONS}

In summary, we have shown that pulsed-field gradient (PFG) NMR together with external calibration curves can be used to obtain information on the interaction of gold(I) complexes with their counterion and substrates. While the original calibration curves derived for compounds with low molecular density are not applicable to gold complexes, a new set of parameters provides estimates of molecular weight with a much-improved accuracy. This is illustrated with several 
cationic gold complexes, counterions and complexation with alkynes. The proposed approach is straightforward and has the potential to help in the understanding of the mechanism of goldcatalysed reactions.

\section{METHODS}

The external calibration curve (ECC) approach is briefly described here, for a more detailed explanation, see ref ${ }^{36}$ Diffusion coefficients obtained from pulsed-field gradient (PFG) NMR experiments are highly sensitive to experimental conditions and parameters. In order to attenuate the influence of sources of systematic errors (e.g. gradient calibration, temperature effects...), the diffusion coefficient measured for the compound of interest $D_{x}$ is divided by that of a reference compound $D_{\text {ref }}$ present in the solution. Then, the resulting relative diffusion coefficient is multiplied by a so-called "fixed" value of the diffusion coefficient of the reference compound $D_{\text {ref,fix, }}$ so that the same calibration curve can be used irrespective of the choice of the reference compound. This "fixed" value is obtained by means of a series of measurements carried out on the reference compound in identical experimental conditions. These quantities are usually manipulated in log form, and the resulting definition of the normalized diffusion coefficient $D_{x, \text { norm is: }}$

(1) $\log \left(D_{x, \text { norm }}\right)=\log \left(D_{x}\right)-\log \left(D_{\text {ref }}\right)+\log \left(D_{\text {ref }, \text { fix }}\right)$

The calibration curve approach then relies on the empirical assumption that a power law relates the normalized diffusion coefficient and the molecular weight of the analyte:

(2) $\log \left(D_{x, \text { norm }}\right)=\log (k)+\alpha \log (M W)$ 
The parameters $k$ and $\alpha$ are obtained from a linear regression between $\log \left(D_{x, \text { norm }}\right)$ and the known molecular weight for a series of compounds. Once the ECC parameters $k$ and $\alpha$ are determined, the molecular weight of an unknown compound can be estimated with the relationship:

(3) $M W_{\text {estimated }}=10^{\left(\frac{\log \left(D_{x, n o r m}\right)-\log (k)}{\alpha}\right)}$

\section{EXPERIMENTAL SECTION}

\section{Sample preparation for the neutral gold complexes $\mathrm{LAuX}$ or $\mathrm{L}-(\mathrm{AuX})_{2}(\mathrm{X}=\mathrm{Cl}, \mathrm{Br}, \mathrm{OH})$}

For each gold complex, a solution was prepared in $600 \mu \mathrm{L}$ of $\mathrm{CD}_{2} \mathrm{Cl}_{2}$, at a concentration of 33 $\mathrm{mM}$. In each solution, adamantane was added at a concentration of $33 \mathrm{mM}(2.7 \mathrm{mg})$ to be used as a reference. Undeuterated dichloromethane $\left(\mathrm{CH}_{2} \mathrm{Cl}_{2}\right)$ was also added, at a concentration of 33 $\mathrm{mM}(1.7 \mathrm{mg})$, for a separate application. In the following, the resonances of $\mathrm{CH}_{2} \mathrm{Cl}_{2}$ and $\mathrm{CDHCl}_{2}$ were integrated simultaneously.

\section{Sample preparation for the cationic gold complexes $[\mathrm{LAu}]^{+}[\mathrm{OTf}]^{-}$}

The gold chloride precursor ((JohnPhos)AuCl, $10.6 \mathrm{mg}$; (IPr)AuCl, 12.4 mg; or $\left.\left(\mathrm{Ph}_{3} \mathrm{P}\right) \mathrm{AuCl}\right)$, $9.9 \mathrm{mg})$ was weighted into a glass vial. $\mathrm{CD}_{2} \mathrm{Cl}_{2}(600 \mu \mathrm{L})$ was then added using a syringe. Silver triflate (5.14 $\mathrm{mg}, 1$ equiv) was added and the vial was sonicated for $3 \mathrm{~min}$ at room temperature. The content of the vial was filtered over celite and the clear solution was transferred into the NMR tube previously charged with adamantane $(5 \mathrm{mg})$. Undeuterated dichloromethane $\left(\mathrm{CH}_{2} \mathrm{Cl}_{2}\right)$ was also added $(3 \mu l)$ in the case of $[(\mathrm{JohnPhos}) \mathrm{Au}]^{+}[\mathrm{OTf}]^{-}$.

\section{NMR experiments}


All the experiments were performed on a $600 \mathrm{MHz}$ Bruker Avance spectrometer using a $5 \mathrm{~mm}$ TXI probe with actively shielded triple-axis gradients, at a nominal temperature of $298 \mathrm{~K}$. Sample spinning was deactivated. All the DOSY experiments were performed using a double stimulated echo sequence with bipolar gradient pulses with convection compensation. The diffusion time ranged from 150 to $230 \mathrm{~ms}$. The delay for gradient recovery was $0.2 \mathrm{~ms}$ and the eddy current delay $5 \mathrm{~ms}$. For each DOSY-NMR experiment, a series of 8 spectra of 32768 data points were collected with a total experiment time of $22 \mathrm{~min}$. The gradient amplitude was incremented from 6.5 to $45.5 \mathrm{Gcm}^{-1}$ of the maximum gradient strength in a linear ramp. Diffusion coefficients were calculated by a mono-exponential fit with the T1/T2 analysis module of the topspin software or the Dynamics Center software (Bruker, Billerica, U.S.A.).

The diffusion coefficients of 13 gold complexes were measured in deuterated dichloromethane solvent and adamantane was used as an internal reference to establish the calibration curves. Undeuterated dichloromethane was also employed to test the possibility to use another internal reference, using ECCs calculated with adamantane. The "fixed" diffusion coefficients of adamantane and dichloromethane ( $\left.D_{\text {ref, fix }}\right)$ were determined by averaging the values obtained in 13 separate experiments.

\section{Molecular geometry}

The geometries of the gold complexes $(\mathbf{a}, \mathbf{b}, \mathbf{c}, \mathbf{d}, \mathbf{e}, \mathbf{g}, \mathbf{i}, \mathbf{l})$ were obtained from the CCDC Xray structure database when available. All other structures for complexes $(\mathbf{f}, \mathbf{h}, \mathbf{j}, \mathbf{k}, \mathbf{m})$ were optimized using the Gaussian 09 software package at the B3LYP level of density functional theory (DFT). The gold and the bromine atom were described by the LANL2DZ ECP basis set. All other atoms were described by the 6-31G(d,p) basis set (see ESI for details). 


\section{ASSOCIATED CONTENT}

Supporting Information

The Supporting Information is available free of charge on the ACS Publications website

\section{AUTHOR INFORMATION}

Corresponding Author

*Address: Institut de Chimie des Substances Naturelles. CNRS UPR2301 Univ. Paris Sud.

Université Paris-Saclay. 91190 Gif-Sur-Yvette France. Email : jeannicolas.dumez@cnrs.fr.

\section{Author Contributions}

The manuscript was written through contributions of all authors.

Notes The authors declare no competing financial interest.

\section{ACKNOWLEDGMENT}

This research was supported by the LabEx Charmmmat (ANR-11-LABX-0039) and the Agence Nationale de la Recherche (ANR-16-CE29-0012). The authors thank Arnaud Voituriez for providing some of the gold complexes.

\section{REFERENCES}

1. Hashmi, A. S. K., Gold-Catalyzed Organic Reactions. Chem. Rev. 2007, 107, 3180-3211.

2. Li, Z.; Brouwer, C.; He, C., Gold-Catalyzed Organic Transformations. Chem. Rev. 2008, 108, 3239-3265.

3. Jiménez-Núñez, E.; Echavarren, A. M., Gold-Catalyzed Cycloisomerizations of Enynes: A Mechanistic Perspective. Chem. Rev. 2008, 108, 3326-3350.

4. Fürstner, A., Gold and platinum catalysis-a convenient tool for generating molecular complexity. Chem. Soc. Rev. 2009, 38, 3208-3221.

5. Huang, H.; Zhou, Y.; Liu, H., Recent advances in the gold-catalyzed additions to C-C multiple bonds. Beilstein J. Org. Chem. 2011, 7, 897-936. 
6. Wang, Y.-M.; Lackner, A. D.; Toste, F. D., Development of Catalysts and Ligands for Enantioselective Gold Catalysis. Acc. Chem. Res. 2014, 47, 889-901.

7. Obradors, C.; Echavarren, A. M., Gold-Catalyzed Rearrangements and Beyond. Acc. Chem. Res. 2014, 47, 902-912.

8. Fürstner, A., From Understanding to Prediction: Gold- and Platinum-Based $\pi$-Acid Catalysis for Target Oriented Synthesis. Acc. Chem. Res. 2014, 47, 925-938.

9. Zhang, Y.; Luo, T.; Yang, Z., Strategic innovation in the total synthesis of complex natural products using gold catalysis. Nat. Prod. Rep. 2014, 31, 489-503.

10. Dorel, R.; Echavarren, A. M., Gold(I)-Catalyzed Activation of Alkynes for the Construction of Molecular Complexity. Chem. Rev. 2015, 115, 9028-9072.

11. Joost, M.; Amgoune, A.; Bourissou, D., Reactivity of Gold Complexes towards Elementary Organometallic Reactions. Angew. Chem. Int. Ed. 2015, 54, 15022-15045.

12. Pflasterer, D.; Hashmi, A. S. K., Gold catalysis in total synthesis - recent achievements. Chem. Soc. Rev. 2016, 45, 1331-1367.

13. Zi, W.; Dean Toste, F., Recent advances in enantioselective gold catalysis. Chem. Soc. Rev. 2016, 45, 4567-4589.

14. Miró, J.; del Pozo, C., Fluorine and Gold: A Fruitful Partnership. Chem. Rev. 2016, 116, $11924-11966$.

15. Wei, Y.; Shi, M., Divergent Synthesis of Carbo- and Heterocycles via Gold-Catalyzed Reactions. ACS Catal. 2016, 6, 2515-2524.

16. Stathakis, C. I.; Gkizis, P. L.; Zografos, A. L., Metal-catalyzed cycloisomerization as a powerful tool in the synthesis of complex sesquiterpenoids. Nat. Prod. Rep. 2016, 33, 10931117.

17. Li, Y.; Li, W.; Zhang, J., Frontispiece: Gold-Catalyzed Enantioselective Annulations. Chem. Eur. J. 2017, 23, 467.

18. Johnson, C. S., Diffusion ordered nuclear magnetic resonance spectroscopy: principles and applications. Prog. Nucl. Magn. Reson. Spectrosc. 1999, 34, 203-256.

19. Macchioni, A.; Ciancaleoni, G.; Zuccaccia, C.; Zuccaccia, D., Determining accurate molecular sizes in solution through NMR diffusion spectroscopy. Chem. Soc. Rev. 2008, 37, 479-489.

20. Pregosin, P. S.; Kumar, P. G. A.; Fernández, I., Pulsed Gradient Spin-Echo (PGSE) Diffusion and 1H,19F Heteronuclear Overhauser Spectroscopy (HOESY) NMR Methods in Inorganic and Organometallic Chemistry: Something Old and Something New. Chem. Rev. 2005, 105, 2977-2998.

21. Edward, J. T., Molecular volumes and the Stokes-Einstein equation. J. Chem. Educ. 1970, 47, 261-270.

22. Einstein, A., Über die von der molekularkinetischen Theorie der Wärme geforderte Bewegung von in ruhenden Flüssigkeiten suspendierten Teilchen. Ann. Phys. (Berlin) 1905, 322, 549-560.

23. Kumar, P. G. A.; Pregosin, P. S.; Schmid, T. M.; Consiglio, G., PGSE diffusion, 1H-19F HOESY and NMR studies on several [Rh(1,5-COD)(Biphemp)]X complexes: detecting positional anion effects. Magn. Reson. Chem. 2004, 42, 795-800.

24. Kumar, P. G. A., PGSE Diffusion NMRAn Emerging Technique for Inorganic/Organometallic Chemists. Aust. J. Chem. 2006, 59, 78-78.

25. Pregosin, P. S., Ion pairing using PGSE diffusion methods. Prog. Nucl. Magn. Reson. Spectrosc. 2006, 49, 261-288. 
26. Abadie, M. A.; Trivelli, X.; Duhal, F. M. N.; Kouach, M.; Linden, B.; Vandewalle, E. G. M.; Capet, F.; Roussel, P.; Rosal, I. D.; Maron, L.; Agbossou-Niedercorn, F.; Michon, C., Gold(I)-Catalysed Asymmetric Hydroamination of Alkenes: A Silver- and Solvent-Dependent Enantiodivergent Reaction. Chem. Eur. J. 2017, 23, 10777-10788.

27. Rocchigiani, L.; Jia, M.; Bandini, M.; Macchioni, A., Assessing the Role of Counterion in Gold-Catalyzed Dearomatization of Indoles with Allenamides by NMR Studies. ACS Catal. 2015, 5, 3911-3915.

28. Evans, R.; Dal Poggetto, G.; Nilsson, M.; Morris, G. A., Improving the Interpretation of Small Molecule Diffusion Coefficients. Anal. Chem. 2018, 90, 3987-3994.

29. Evans, R.; Deng, Z.; Rogerson, A. K.; McLachlan, A. S.; Richards, J. J.; Nilsson, M.; Morris, G. A., Quantitative Interpretation of Diffusion-Ordered NMR Spectra: Can We Rationalize Small Molecule Diffusion Coefficients? Angew. Chem., Int. Ed 2013, 52, 3199-3202. 30. Chen, A.; Wu, D.; Johnson, C. S., Determination of Molecular Weight Distributions for Polymers by Diffusion-Ordered NMR. J. Am. Chem. Soc. 1995, 117, 7965-7970.

31. Li, D.; Keresztes, I.; Hopson, R.; Williard, P. G., Characterization of Reactive Intermediates by Multinuclear Diffusion-Ordered NMR Spectroscopy (DOSY). Acc. Chem. Res. 2009, 42, 270-280.

32. Viel, S.; Capitani, D.; Mannina, L.; Segre, A., Diffusion-Ordered NMR Spectroscopy: A Versatile Tool for the Molecular Weight Determination of Uncharged Polysaccharides. Biomacromolecules 2003, 4, 1843-1847.

33. Li, D.; Kagan, G.; Hopson, R.; Williard, P. G., Formula Weight Prediction by Internal Reference Diffusion-Ordered NMR Spectroscopy (DOSY). J. Am. Chem. Soc. 2009, 131, 56275634.

34. Li, D.; Sun, C.; Liu, J.; Hopson, R.; Li, W.; Williard, P. G., Aggregation Studies of Complexes Containing a Chiral Lithium Amide and n-Butyllithium. J. Org. Chem. 2008, 73, 2373-2381.

35. Hamdoun, G.; Sebban, M.; Cossoul, E.; Harrison-Marchand, A.; Maddaluno, J.; Oulyadi, H., 1H Pure Shift DOSY: a handy tool to evaluate the aggregation and solvation of organolithium derivatives. Chem. Commun. 2014, 50, 4073-4075.

36. Neufeld, R.; Stalke, D., Accurate molecular weight determination of small molecules via DOSY-NMR by using external calibration curves with normalized diffusion coefficients. Chem. Sci. 2015, 6, 3354-3364.

37. Bachmann, S.; Neufeld, R.; Dzemski, M.; Stalke, D., New External Calibration Curves (ECCs) for the Estimation of Molecular Weights in Various Common NMR Solvents. Chem.

Eur. J. 2016, 22, 8462-8465.

38. Kreyenschmidt, A. K.; Bachmann, S.; Niklas, T.; Stalke, D., Molecular Weight Estimation of Molecules Incorporating Heavier Elements from van-der-Waals Corrected ECCDOSY. ChemistrySelect 2017, 2, 6957-6960.

39. Bachmann, S.; Gernert, B.; Stalke, D., Solution structures of alkali metal cyclopentadienides in THF estimated by ECC-DOSY NMR-spectroscopy (incl. software). Chem. Commun. 2016, 52, 12861-12864.

40. Neufeld, R.; John, M.; Stalke, D., The Donor-Base-Free Aggregation of Lithium Diisopropyl Amide in Hydrocarbons Revealed by a DOSY Method. Angew. Chem. Int. Ed. 2015, 54, 6994-6998. 
41. Wang, Z. J.; Benitez, D.; Tkatchouk, E.; Goddard Iii, W. A.; Toste, F. D., Mechanistic Study of Gold(I)-Catalyzed Intermolecular Hydroamination of Allenes. J. Am. Chem. Soc. 2010, 132, 13064-13071.

42. Zhdanko, A.; Maier, M. E., The Mechanism of Gold(I)-Catalyzed Hydroalkoxylation of Alkynes: An Extensive Experimental Study. Chem. Eur. J. 2014, 20, 1918-1930.

43. Kovács, G.; Ujaque, G.; Lledós, A., The Reaction Mechanism of the Hydroamination of Alkenes Catalyzed by Gold(I)-Phosphine: The Role of the Counterion and the N-Nucleophile Substituents in the Proton-Transfer Step. J. Am. Chem. Soc. 2008, 130, 853-864.

44. Brown, T. J.; Widenhoefer, R. A., Cationic Gold(I) $\pi$-Complexes of Terminal Alkynes and Their Conversion to Dinuclear $\sigma, \pi$-Acetylide Complexes. Organometallics 2011, 30, 60036009.

45. Brooner, R. E. M.; Widenhoefer, R. A., Cationic, Two-Coordinate Gold $\pi$ Complexes. Angew. Chem. Int. Ed. 2013, 52, 11714-11724.

46. Jones, A. C., Gold $\pi$-Complexes as Model Intermediates in Gold Catalysis. In Homogeneous Gold Catalysis, Slaughter, L. M., Ed. Springer International Publishing: Cham, 2015; pp 133-165.

47. S V Kharlamov, S. K. L., Modern diffusion-ordered NMR spectroscopy in chemistry of supramolecular systems: the scope and limitations. RUSS CHEM REV, 2010, 79 (8), 635-653.

48. Neufeld, R.; Teuteberg, T. L.; Herbst-Irmer, R.; Mata, R. A.; Stalke, D., Solution

Structures of Hauser Base iPr2NMgCl and Turbo-Hauser Base iPr2NMgCl$\cdot \mathrm{LiCl}$ in THF and the Influence of $\mathrm{LiCl}$ on the Schlenk-Equilibrium. J. Am. Chem. Soc. 2016, 138, 4796-4806.

49. Reich, H. J., Role of Organolithium Aggregates and Mixed Aggregates in Organolithium Mechanisms. Chem. Rev. 2013, 113, 7130-7178.

50. Barozzino-Consiglio, G.; Hamdoun, G.; Fressigné, C.; Harrison-Marchand, A.; Maddaluno, J.; Oulyadi, H., A Combined 1H/6Li NMR DOSY Strategy Finally Uncovers the Structure of Isopropyllithium in THF. Chem. Eur. J. 2017, 23, 12475-12479. 


\section{Toc graphic}

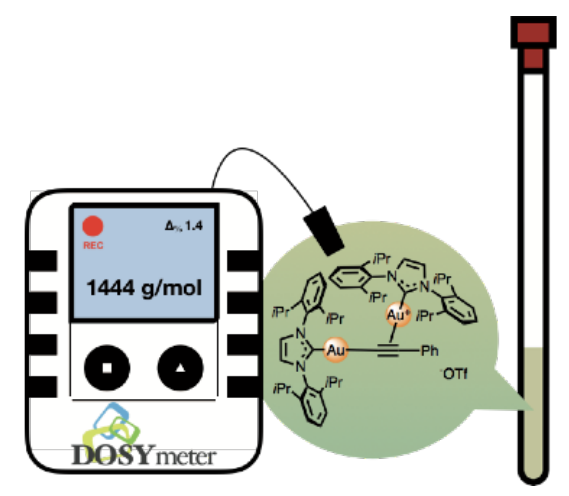

